\title{
Unreadable
}

$\mathrm{M}$ y father picked me up after school on my last day of junior high. As I showed him my final report card, tears ran down his face. He cried with pride, because he knew how hard I had had to work to scrape a borderline pass, and he cried with sadness for what this would mean for my future.

I had barely made it. I spent countless hours torturing my eyes with letters that slid away. No matter how diligently I threw myself at the slope of institutionalized education, my results kept slipping. My teachers didn't know why. They thought I was just plain stupid.

What takes the average person five minutes to read takes me thirty. Reading for me is like trying to sprint in water. My eyes move quickly across the page, but my mind cannot process the words in time. The words bounce off a brick wall in my head. The only way they break through is if I force myself to read at a much slower pace.

My father struggled as well. He nearly killed himself earning his master of business administration degree, and couldn't understand why he floundered so much more than his peers. In his day, if you couldn't keep up, you were the problem. It was brutal for him, but it also gave him absolute faith that if he could survive in such a callous world, so could I. This time my parents set out to figure out what had plagued him and now plagued me. At 12 years of age, I was diagnosed with a severe reading disability. Fortunately, didactics had progressed since my father's day and slowly, teachers began to understand that having a learning disability did not mean an inability to learn. It simply required a different approach.

Two realizations came out of my diagnosis:

1. I could succeed.

2. It would not be easy.

I gave up all my nights and weekends and devoted myself to my studies,

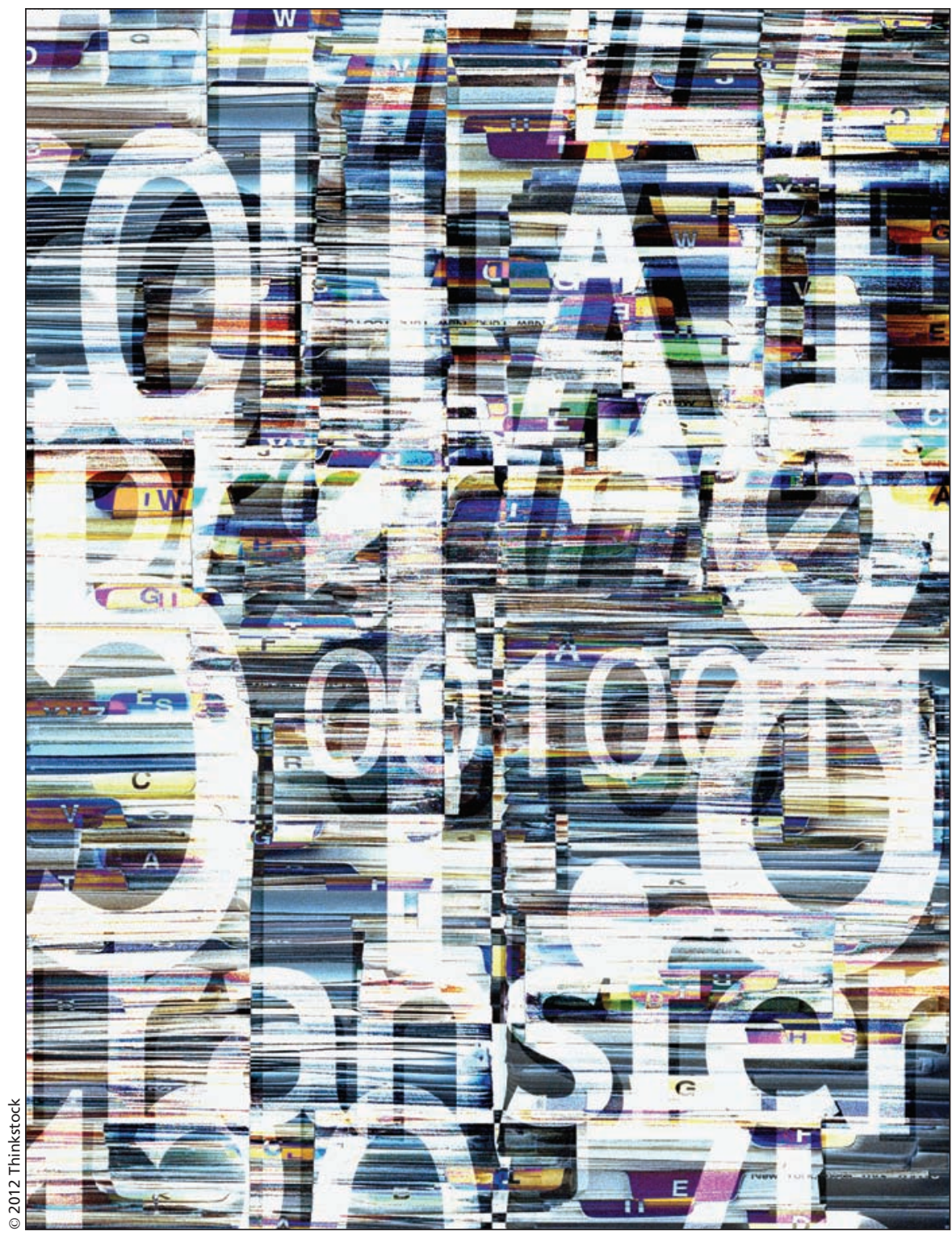

with little to show for it. My parents were constantly urged to put me in the non-university stream for high school.

The one truth of living with a constant disability is this. There is no panacea, no magic pill. I still struggle to this day. Instead, you try to manage your weakness and pray that you find mentors who understand your troubles, believe in you, and give you a chance. With support and proper accommodations, I learned to block out any noise or slight distraction that could disrupt my concentration. After months of work, material finally began to sink in. My marks improved. It felt like a miracle. Then the unthinkable happened. I was accepted to the University of Calgary to study science, and then pharmacy at the University of British Columbia. Getting into pharmacy and 
succeeding confirmed my capabilities and empowered me to finally admit my dream of becoming a physician.

I went for it, and promptly found myself struggling to achieve medical school requirements while finishing a grueling professional degree. A plethora of new and complex tasks bombarded me. Time was running out. I lost all sense of control over my disability. Frustrated, I became my own worst critic. I burnt myself out, mired in a sense of constant failure. When I read, the words collapsed into a jumbled mess on the page. Every breath I took added kindling to a fire of anxiety deep inside my chest. I was losing control of my mind, my sanity and my future. Something had to change. Slowly, I began to accept my disability and limitations. Instead of reading things over and over, I wrote everything out wordby-word, and painstakingly recited my notes, as though memorizing lines for a play. Slowly, material began to stick in my brain. I applied to medical school and crossed my fingers.

Now here I am, a third-year medical student in the heart of my clinical clerkship year. Clerkship requires fast and efficient learning. The conundrum: learning in a constantly accelerating environment with a disability that slows me down. But I have one weapon: the determination to stick with something until I succeed. Something my childhood taught me in spades.

The hardest part of this journey has been learning to accept a part of me that I have kept hidden not only from the outside world, but also from myself. For years, I was afraid of the stigma that often comes with revealing a deeply personal and little-understood weakness. Yet only when I accepted my issues could I work through them and finally learn to cope.

Now as a medical student, I look at things differently. When I see the new challenges and struggles my patients face in tackling their new diagnoses, addictions and disabilities, I'm reminded of my personal struggle in tackling my disability. I feel the frustration they feel when their health care goals and challenges are not properly understood by those who care for them, just as my disability was at times not understood by those in charge of my education. In a system where so many are lost to follow-up, I see the power of what we as physicians can accomplish for our patients when we advocate for them, the same way those who advocated for me made such a positive impact on my life. What once seemed like such a burden now serves as my greatest asset in being compassionate toward my patients. It makes me human.

Daniel J. Heffner BSc (Pharm)

Class of 2013

Faculty of Medicine

University of British Columbia

Vancouver, BC

CMAJ 2012. DOI:10.1503/cmaj.111810

\section{Mapping as methodology}

\section{Disease Maps: Epidemics on the Ground Tom Koch \\ University of Chicago Press; 2011.}

I $\mathrm{t}$ is almost impossible to attend a public health conference in Canada nowadays without some mention in the proceedings about the "built environment." Study within this emerging field looks at the interrelationship between urban design and its impact on sustainable, healthy living. Mapping the proximity of fastfood outlets to neighbourhood clusters of diabetes is one illustration of an exploratory study under this theme. Although the data produce products from digitalized geospatial analysis about the association between urban environmental features and chronic disease rates that may be relatively new, any delusion that mapping as a methodology is similarly new is quickly dispelled by Koch's founda-

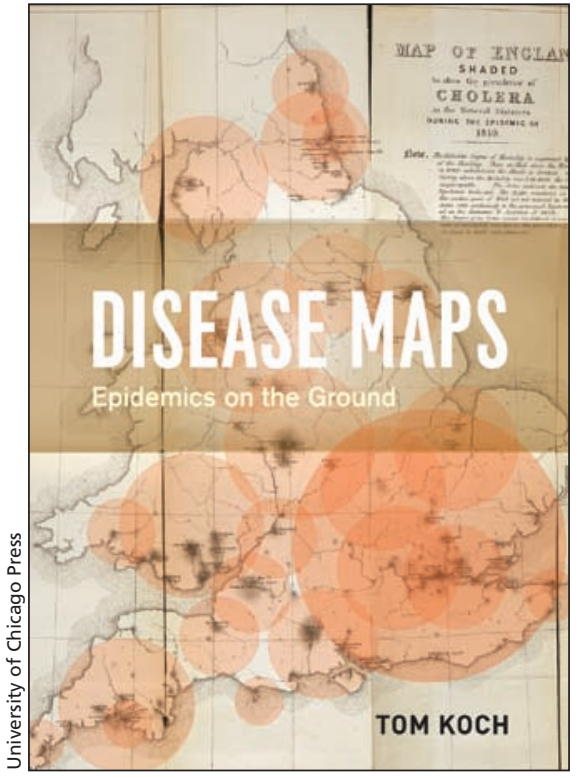

tional book, Disease Maps: Epidemics on the Ground. Maps have informed public health theory, investigations, understanding and political decisions for centuries.
Koch's stately text develops and illustrates the argument that mapping the spatial relationships between disease and posited environmental influences is a methodology. As such, maps carry the exciting potential to identify and establish new empirical associations, yet they are susceptible to the same limitations of data accuracy and investigator biases as any other methodology - maybe even more so given our inherent tendency to conform visual information to known patterns. Readers forewarned: this can be especially concerning in the arena of public health when the backdrop to spatial patterns may be outlined by pre-existing political boundaries.

The author guides the reader through the maturation and exposition of disease mapping as a methodology in a series of 12 chapters divided into three sections, each supported by an impressive collection of archival maps and illustrations. The first section introduces the concept 